Copyright (C) 2015 by Academic Publishing House Researcher

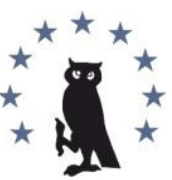

Published in the Russian Federation

European Researcher

Has been issued since 2010.

ISSN 2219-8229

E-ISSN 2224-0136

Vol. 92, Is. 3, pp. 222-229, 2015

DOI: 10.13187/er.2015.92.222

www.erjournal.ru

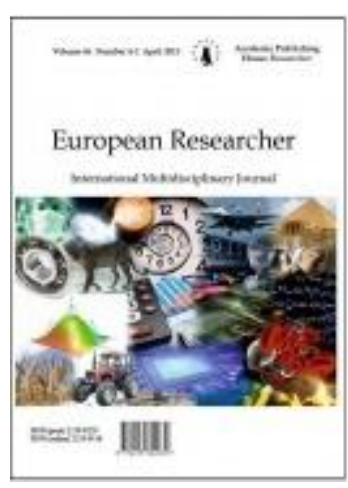

Psychological sciences

Психологические науки

UDC 159.9

\title{
People with Dementia in the Community: Satisfaction with Life and Health-related Quality of Life
}

\author{
1,2 Alexandra Pereira \\ 1,2 Amelia Ferreira \\ 1,3 Jose Martins
}

${ }^{1}$ University of Oporto, Porto, Portugal

${ }^{2}$ Community Care Unit, UCC Lousada, Lousada, Portugal

${ }_{3}^{3}$ School of Nursing, Coimbra, Portugal

${ }^{1,2} \mathrm{RN}$, MSc Palliative Care, PhDs Nursing Sciences

E-mail: alemnap@gmail.com

1, 2 RN, MSc Palliative Care, PhDs Nursing Sciences

E-mail: amelia.leite.ferreira@gmail.com

1,3 RN, MSc Nursing Sciences, PhD Nursing Sciences

E-mail: jmartins@esenfc.pt

\begin{abstract}
Purpose: To assess the satisfaction with life and health-related quality of life of patients with dementia living in the community.

Design/methodology/approach: Cross-sectional study. A questionnaire was administered to 50 subjects identified in the community. Instruments used included the EQ-5D, Satisfaction With Life Scale (SWLS) and Barthel Index (BI).

Findings: It is possible to use a self-report approach with EQ-5D and SWLS as assessment measures in the Portuguese community context. EQ-5D average score was 0,43 points and EQ-VAS average score was 56,04 points. SWLS average score was 17,32 points. BI average score was 13,82 points.

Originality/value: This study is the first to assess the health-related quality of life of patients with the dementia exclusively in the Portuguese community context.

Keywords: Dementia; Health-related Quality of life; Community; Mental Health.

\section{Introduction}

Dementia is an irreversible, progressive and organic mental disorder that may be caused by many conditions (1). In fact, the term 'dementia' is usually used to define a group of symptoms that can include memory loss, decline of communication skills and gradual skill loss to carry out daily activities (2).
\end{abstract}


The four main subtypes of dementia identified in the community are Alzheimer's Disease (31,0 \%), Vascular Dementia (22,0 \%), Lewy Body Dementia (11,0 \%) and Frontal Lobe Dementia $(7,8 \%)(3)$.

The estimated life expectancy for a person with dementia is 4,5 years, but it can be up to 10,7 years, depending on the age and existing comorbidities at the time of diagnosis (4).

More than 7,3 million Europeans have dementia. In Portugal, the estimated prevalence is 153,000 people. It is also estimated that these numbers will double in 40 years $(5)$.

The major risk factor for dementia is age and so, the incidence of dementia rises with age (Alzheimer Europe, 2009; Knapp \& Prince, 2007). The incidence of dementia doubles every 5,9 years. Annually, there are 7,7 million new cases of dementia in the world. That is 1 new case every 4 seconds (6).

In consonance with the world's and European's reality, the Portuguese reality is one of aging population. In 2010, $17,90 \%$ of the Portuguese population was over 65 years old and $4.60 \%$ was over 80 years old. Estimations predict these numbers will double in 2050 and triple in 2100 and are above the average estimated for Europe and entire world (7).

Regarding the above, dementia has become a major public health problem. It represents a major cause of morbidity and mortality for the older population (8) and creates challenges for societies, health and social care professionals (9). This is even more important in the Portuguese community context. As dementia has a long evolution course, the majority of people with dementia live at their homes (10).

Even so, there's growing evidence that people with dementia can have a meaningful life, if provided adequate support to foment the ability to cope with the disease (11). In the instance, the assessment of patient needs and the evaluation of determinants of quality of life are priorities in dementia care (Alzheimer Europe, 2009; Alzheimer's Disease International, 2009).

Quality of life is a broad concept of complex definition (12). In the dementia context, the assessment of quality of life is very challenging. Even though there are assessment approaches of direct observation of behaviors and activities and proxy-report by caregivers or healthcare professionals, this paper centers attention on the approach of self-report by the person with dementia (13).

Although there are several validated assessment measures, the ones that were chosen to this study were selected according to the care setting and severity of dementia and are recommended measures by the cerebral aging and Dementia Group Study of Coimbra, Portugal.

This study aimed to evaluate the satisfaction with life and health-related quality of life of people with dementia living in the community. A quantitative approach was chosen, using a crosssectional study.

\section{Method}

\section{Patient Sample}

A convenience sample of 50 patients was enrolled. As it is difficult to identify patients with dementia living in the community using a systematic method, the subjects were recruited by one health care center and two dementia non-profit organizations. The patient population was not hospitalized or institutionalized. To take part of the study, subjects had to be over 18 years old, native Portuguese speakers and present a dementia diagnosis for more than 6 months.

Regarding previous studies and due to the particular problems in this population, it was decided that the questionnaire could be administered by a trained healthcare professional.

\section{Data collection and instruments}

For each person with dementia, a questionnaire including social demographic information and time of diagnosis was applied, between January 2013 and April 2013. Patient's dementia stage was mild or moderate, according to Hughes' Clinical Dementia Rating Scale (14).

Barthel Index was used to record the consequences of dementia in patient's functioning and level of dependency. IB measures the patient's performance on basic activities of daily living (selfcare, hygiene, dressing, eating and sphincter continence). The maximum score is 20 (independence) and minimum is $\mathrm{o}$ (total dependence).

The EQ-5D was used to record the patient's health-related quality of life. The EQ-5D evaluates the patient's health state "today" on five dimensions: mobility, self-care, usual activities, 
pain/discomfort and anxiety/depression. For each dimension, a one to three scale is used (no problem, some degree of the problem and extreme problem). The patient's responses may be used to create a profile or score. The valued UK time trade-off social tariff of health state was used. A general question is also part of this instrument which compares the actual and one year ago health state. This instrument also has a visual analogue scale (EQ-VAS) scaled from o (worse imaginable health state) to 100 (best imaginable health state). The EQ- $5 \mathrm{D}$ has been translated into several languages and has been validated and used in several studies regarding general populations, different disease groups and also people with dementia.

The SWLS was used to assess the global satisfaction with life, reflecting subjective well-being. This 5-item instrument evaluates one's subjective judgment on their quality of life, according to self-determined criteria instead of imposed external patterns. The maximum score is 35 and minimum score is 5 . Higher score indicate higher satisfaction with life.

\section{3. $\quad$ Statistical analysis}

The SPSS (version 19.0 for Windows) was used to analyze the data.

\subsection{Acceptability}

Fifty patients were recruited and accepted to complete the questionnaire. There were no refusals to participate and all questionnaires were suitable for analysis.

\subsection{Feasibility}

All 50 patients responded to the questionnaire administered by a healthcare professional. The feasibility of the responses was guaranteed by the acceptation of the questionnaires that had a response rate of $100 \%$.

\subsection{Reliability}

Internal consistency was determined using Cronbach's $\alpha$ (minimum acceptable was 0,70) (15) and corrected item-total correlation (minimum acceptable was 0,40) (16).

The reliability analysis revealed SWLS Cronbach's $\alpha$ of 0,75 and EQ-5D Cronbach's $\alpha$ of 0,75. The SWLS and EQ-5D corrected item-total correlation showed values $\geq 0,40$ in the majority of the items (Table 1).

Table 1: SWLS and EQ-5D item reliability

\begin{tabular}{|c|c|c|c|}
\hline \multicolumn{2}{|c|}{ SLWS } & \multicolumn{2}{c|}{ EQ-5D } \\
\hline Question & Corrected Item-total Correlation & Dimension & $\begin{array}{c}\text { Corrected Item-total } \\
\text { Correlation }\end{array}$ \\
\hline 1 & 0,55 & Mobility & 0,76 \\
\hline 2 & 0,63 & Self-care & 0,66 \\
\hline 3 & 0,64 & Usual activities & 0,61 \\
\hline 4 & 0,65 & Pain/discomfort & 0,48 \\
\hline 5 & 0,21 & Anxiety/depression & 0,15 \\
\hline
\end{tabular}

\section{Ethical Procedures}

Ethical approval for the study was obtained from the Research Unit in Health Sciences Nursing School of Coimbra Ethics Committee.

Authorization and approval was obtained from the healthcare center and the two dementia non-profit organizations prior to the implementation of the study. Also, the utilization of the instruments was authorized by the authors of the Portuguese translation.

Informed consent was obtained from each patient after the study was explained and they had been given an explanatory letter. 


\section{Results}

A total of 50 patients were included in the study (Table 2). There were 21 men (42,00 \%) and 29 women (58,00 \%). The average age was 78,64 years, with a range of 46 to 94 years. The majority of the patients were married (46,00 \%) or widowed (46,00 \%).

The school years of the sample was 2,88 years in average. Regarding the household composition, the patient with dementia lived in the community with 2,20 people in average.

As measured with the CDR, 40,00\% had mild dementia and 60,00\% had moderate dementia and were diagnosed 4,76 years ago (average).

The IB average score obtained was 13,82 points. The maximum score obtained was 20 points and the minimum was 2 points. Regarding the level of dependency, the majority had moderate dependency $(46,00 \%)$.

Table 2: Subject characteristics at selection

\begin{tabular}{|c|c|c|}
\hline & & Total \\
\hline Age & Years (Average) & 78,64 years \\
\hline \multirow{2}{*}{ Sex } & Male & $42,00 \%$ \\
\hline & Female & $58,00 \%$ \\
\hline \multirow{2}{*}{ Religion } & Catholic & $98,00 \%$ \\
\hline & Agnostic & $2,00 \%$ \\
\hline \multirow{4}{*}{ Marital status } & Single & $4,00 \%$ \\
\hline & Married & $46,00 \%$ \\
\hline & Widowed & $46,00 \%$ \\
\hline & Divorced & $4,00 \%$ \\
\hline Education & Years (Average) & 2,88 years \\
\hline $\begin{array}{l}\text { Household Composition (excluding } \\
\text { patient with dementia) }\end{array}$ & Number of People (Average) & 2,20 people \\
\hline \multirow[t]{2}{*}{1} & Mild dementia & $40,00 \%$ \\
\hline & Moderate dementia & $60,00 \%$ \\
\hline Time of Diagnosis & Years (Average) & 4,76 years \\
\hline \multirow{5}{*}{ Barthel Index } & Score (Average) & 13,82 points \\
\hline & Independency & $14,00 \%$ \\
\hline & Moderate dependency & $46,00 \%$ \\
\hline & Severe dependency & $24,00 \%$ \\
\hline & Total dependency & $16,00 \%$ \\
\hline
\end{tabular}

The SWLS average score obtained was 17,32 points. The maximum score obtained was 28 points and the minimum was 5 points.

The EQ-5D average score obtained was 0,43 points. The responses distribution by Dimension can be observed on Table 3. The majority of the subjects had "some problems in walking about" (48,00 \%), "some problems washing or dressing themselves" (40,00 \%), "some problems with performing my usual activities" (48,00 \%), "moderate pain or discomfort" (54,00 \%) and "moderate anxiety or depression" (52,00 \%). Regarding the comparison of the actual and one year ago health state, the majority of the subjects consider to feel worse (48,00 \%). The EQ-VAS average score obtained was 56,04 points. The maximum score obtained was 95,00 points and the minimum was 20,00 points.

Table 3: Responses distribution by EQ-5D Dimension

\begin{tabular}{|l|l|c|}
\hline Dimension & Category & Percentage \\
\hline \multirow{3}{*}{ Mobility } & No problem & $46,00 \%$ \\
\cline { 2 - 3 } & Some problem & $48,00 \%$ \\
\cline { 2 - 3 } & Extreme problem & $6,00 \%$ \\
\hline
\end{tabular}




\begin{tabular}{|l|l|c|}
\hline \multirow{3}{*}{ Self-care } & No problem & $32,00 \%$ \\
\cline { 2 - 3 } & Some problem & $40,00 \%$ \\
\cline { 2 - 3 } & Extreme problem & $28,00 \%$ \\
\hline \multirow{3}{*}{ Usual activities } & No problem & $16,00 \%$ \\
\cline { 2 - 3 } & Some problem & $48,00 \%$ \\
\cline { 2 - 3 } & Extreme problem & $36,00 \%$ \\
\hline \multirow{3}{*}{ Pain/Discomfort } & No problem & $34,00 \%$ \\
\cline { 2 - 3 } & Moderate problem & $54,00 \%$ \\
\cline { 2 - 3 } & Extreme problem & $12,00 \%$ \\
\hline \multirow{3}{*}{ Anxiety/Depression } & No problem & $42,00 \%$ \\
\cline { 2 - 3 } & Some problem & $52,00 \%$ \\
\cline { 2 - 3 } & Extreme problem & $6,00 \%$ \\
\hline
\end{tabular}

\section{Discussion}

Although there's growing attention regarding the quality of life and health necessities of people with dementia, there are few studies that refer the use of a self-report approach.

We found 4 studies that used EQ-5D as assessment measure with a self-report approach from 3 different countries (Ankri, et al., 2003; López-Bastida, et al., 2006; Bhattacharya, et al., 2010; Martín-García, et al., 2013) (Table 4). Three studies are cross-sectional studies and one is a cohort study. According to the context, only one study was applied in the community context, one was applied in the institutional context and two were applied in mixed contexts (community and institutional).

Table 4: Comparison between studies using EQ-5D

\begin{tabular}{|c|c|c|c|c|c|}
\hline & $\begin{array}{c}\text { Pereira, et al. } \\
(2013) \\
(\mathrm{N}=50)\end{array}$ & $\begin{array}{c}\text { Ankri, et al. } \\
(2003) \\
(\mathrm{N}=142)\end{array}$ & $\begin{array}{c}\text { López- } \\
\text { Bastida, et al. } \\
(2006) \\
(\mathrm{N}=237) \\
\end{array}$ & $\begin{array}{l}\text { Bhattacharya, } \\
\text { et al. (2010) } \\
(\mathrm{N}=321)\end{array}$ & $\begin{array}{c}\text { Martín- } \\
\text { García, et al. } \\
(2013) \\
(\mathrm{N}=525) \\
\end{array}$ \\
\hline Country & Portugal & France & Spain & Denmark & Spain \\
\hline Type of Study & $\begin{array}{c}\text { Cross- } \\
\text { sectional }\end{array}$ & $\begin{array}{c}\text { Cross- } \\
\text { sectional }\end{array}$ & $\begin{array}{c}\text { Cross- } \\
\text { sectional }\end{array}$ & Cohort & $\begin{array}{c}\text { Cross- } \\
\text { sectional }\end{array}$ \\
\hline Context & Community & Mixed & Mixed & Community & Institutional \\
\hline Age & 78,64 & 82,9 & 75,5 & 76,2 & $\begin{array}{c}84 \% \geq 80 \\
\text { years }\end{array}$ \\
\hline Gender & $\begin{array}{l}58,00 \% \\
\text { Female }\end{array}$ & $79,6 \%$ Female & $70,9 \%$ Female & $54,8 \%$ Female & $82,7 \%$ Female \\
\hline Marital status & $\begin{array}{c}46,00 \% \\
\text { married } \\
46,00 \% \\
\text { widowed } \\
\end{array}$ & $\begin{array}{c}54,7 \% \\
\text { widowed }\end{array}$ & - & - & $\begin{array}{c}62,6 \% \\
\text { widowed }\end{array}$ \\
\hline $\begin{array}{l}\text { Education } \\
\text { Years }\end{array}$ & $\begin{array}{l}2,88 \text { years } \\
\text { (average) }\end{array}$ & $\begin{array}{c}71,8 \% 6 \text { to } 8 \\
\text { years }\end{array}$ & - & - & $\begin{array}{c}64,8 \% \text { no } \\
\text { education or } \\
\text { incomplete } \\
\text { primary }\end{array}$ \\
\hline $\begin{array}{l}\text { Time of } \\
\text { Diagnosis } \\
\text { (Average) }\end{array}$ & 4,76 years & - & 5,3 years & - & $e^{5}-1-1$ \\
\hline Barthel Index & $\begin{array}{c}13,82 \\
\text { (average } \\
\text { score; o-20; } \\
\text { moderate } \\
\text { dependence) }\end{array}$ & - & $\begin{array}{c}\text { 30,4\% Severe } \\
\text { dependence }\end{array}$ & - & $\begin{array}{c}32,82 \\
\text { (average } \\
\text { score; o-10o; } \\
\text { severe } \\
\text { dependence) }\end{array}$ \\
\hline
\end{tabular}




\begin{tabular}{|l|c|c|c|c|c|}
\hline $\begin{array}{l}\text { EQ-5D } \\
\text { average score }\end{array}$ & 0,43 & $\begin{array}{c}\text { (only reports } \\
\text { results by EQ- } \\
5 \mathrm{D} \\
\text { dimension) }\end{array}$ & 0,29 & 0,86 & 0,11 \\
\hline $\begin{array}{l}\text { EQ-VAS } \\
\text { average score }\end{array}$ & 56,04 & 62,9 & 42,0 & 76,53 & 51,54 \\
\hline
\end{tabular}

The person with dementia profile obtained in our study is similar to the one obtained in the community context by Bhattacharya and coworkers. The majority of the sample are females, although their average age is slightly lower. However, the EQ-5D results between the two samples are very different. Our results report lower EQ-5D and EQ-VAS average scores.

Regarding the French cross-sectional study by Ankri and coworkers, our results report a lower average age and lower average education years. The majority of both samples are female and widowed. Our results report lower EQ-VAS average scores. The results of both studies are similar in the pain/discomfort and anxiety/depression EQ-5D dimensions and are slightly better in the French study in the mobility, self-care and usual activities EQ-5D dimensions, as the majority of the sample reported having "no problem".

The profile obtained in our study is similar to those obtained in the Spanish studies by LópezBastida and coworkers and Martín-Garcia and coworkers. The majority of the three samples are females. The average age in the López-Bastida and coworkers study is slightly lower and in the Martín-García and coworkers study is slightly higher. The sample's education years in the MartínGarcia and coworkers study is similar to ours. The average time of diagnosis is slightly higher in the López-Bastida and coworkers study.

Both Spanish studies report lower results in the average EQ-5D scores and in the average EQVAS scores. However, according to the BI results, our sample is less dependent than those in the Spanish studies. Regarding the EQ-5D average score for general population with similar age without cognitive impairment, our results are lower than those reported in a Portuguese study in rural $(\mathrm{EQ}-5 \mathrm{D}$ average score $=0,70 ; \mathrm{EQ}-\mathrm{VAS}$ average score $=66,07)$ and urban context $(\mathrm{EQ}-5 \mathrm{D}$ average score $=0,67$; EQ-VAS average score $=61,00)(17)$.

We conclude that even though it is possible to use a self-report approach with EQ-5D as assessment measure, the results obtained are heterogeneous regarding different contexts and countries which difficulties the health-related quality of life scores comparison . Thus, more studies using EQ-5D are needed to assess the health-related quality of life of the person with dementia.

The health-related quality of life of Portuguese people with dementia living in the community is lower than the one reported for the elderly Portuguese population.

We found 1 study that used SWLS as assessment measure with a self-report approach (18) (Table 5). It is a Portuguese cross-sectional study that was applied in a mixed context.

Table 5: Comparison between studies using SWLS

\begin{tabular}{|l|c|c|}
\cline { 2 - 3 } \multicolumn{1}{c|}{} & $\begin{array}{c}\text { Pereira, et al. (2013) } \\
(\mathrm{N}=5 \mathrm{O})\end{array}$ & $\begin{array}{c}\text { Bárrios, et al. (2013) } \\
(\mathrm{N}=104)\end{array}$ \\
\hline Country & Portugal & Portugal \\
\hline Type of Study & Cross-sectional & Cross-sectional \\
\hline Context & Community & Mixed \\
\hline Age & 78,64 & 77,30 \\
\hline Gender & $58,00 \%$ Female & $68,3 \%$ Female \\
\hline Marital status & $\begin{array}{c}46,00 \% \text { married } \\
46,00 \% \text { widowed }\end{array}$ & $52,9 \%$ married \\
\hline Education Years (average) & 2,88 years & 8,4 years \\
\hline Time of Diagnosis (Average) & 4,76 years & - \\
\hline Barthel Index & $\begin{array}{c}13,82 \\
\text { (average score; } 0-20)\end{array}$ & - \\
\hline $\begin{array}{l}\text { SWLS } \\
\text { (average score) }\end{array}$ & 17,32 & 21,70 \\
\hline
\end{tabular}


The SWLS average score obtained in our study is lower that the score reported by Bárrios and coworkers. We consider these to be interesting results as both studies were applied in the Portugal. The people with dementia profile obtained in both studies are similar, although there is a considerable difference in the average education years. Bárrios and coworkers study report higher education level.

We also have to consider the difference of both contexts. Bárrios and coworkers study was applied in the south of Portugal, with community and institutionalized patients, as ours was applied in the north of Portugal, with only community patients.

Regarding the SWLS average score for general Portuguese population, our results are lower (19).

Although it is possible to use a self-report approach with SWLS as assessment measure, more studies are needed in different contexts and countries. We also suggest that other variables as the family income should be considered in future studies.

We conclude that people with dementia living in the northern Portuguese community context have lower satisfaction with life than the people with dementia living in the south of Portugal. The same also verifies when compared with the general population.

Limitations of this work that should be addressed in future studies include:

- The limited size of the sample;

- The selection of a convenience sample, and so the results cannot be generalized to the entire population;

- The inclusion of patients with different subtypes of dementia;

- The non-utilization of a screening instrument for cognitive impairment.

\section{Conflict of Interest}

None.

\section{Description of author's roles}

A. Pereira and J. Martins designed the study. A. Pereira and A. Ferreira participated in data collection. A. Pereira and J. Martins supervised data collection. A. Pereira and J. Martins analyzed the data. A. Pereira wrote the paper. A. Ferreira and J. Martins assisted the writing of the paper.

\section{Acknowledgments}

We are grateful to all the participants in the study and to the colleagues of the Group of Health Care Centers ACeS Tamega III-Vale do Sousa Norte, UCC Lousada, Alzheimer Portugal Association and Sorrisos do Coraçao Association, for their collaboration and contribution with data collection.

\section{References:}

1. Lloyd-Williams, M. \& Payne, S., 2002. Can Multidisciplinary Guidelines Improve The Palliation Of Symptoms In The Terminal Phase Of Dementia?. International Journal of Palliative Nursing, 8(8), pp. 370-5. Society.

2. Knapp, M. \& Prince, M., 2007. Dementia UK: The Full Report, London: Alzheimer's

3. Stevens, T. et al., 2002. Islington Study Of Dementia Subtypes In The Community. The British Journal of Psychiatry, Volume 180, pp. 270-6.

4. Goodman, C. et al., 2010. End of Life Care for Community Dwelling Older People with Dementia: an integrated review. International Journal of Geriatric Psychiatry, 25(4), pp. 329-337.

5. Alzheimer Europe, 2009. Alzheimer Europe (2009) - Plano Nacional de Intervenção da Alzheimer Portugal. [Online] Available at: http://www.alzheimereurope.org/content/download/ 9836/88093/file/Proposed\%20 National\%20Strategy\%2oby\%20Alzheimer\%20Portugal\%20 (in\% 20 Portuguese).pdf[Accessed 9 September 2012].

6. Alzheimer's Disease International, 2009. World Alzheimer's Report, London: Alzheimer's Disease International.

7. ONU - United Nations Department Of Economic And Social Affairs, 2010. World Population Prospects, The 2010 Revision. [Online] Available at: http://esa.un.org/wpp/ExcelData/population.htm[Accessed 9 September 2012]. 
8. MCCarthy, M., Addington-Hall, J. \& Altmann, D., 1997. The experience of dying with dementia: a retrospective study. International Journal of Geriatric Psychiatry, 12(3), pp. 404-9.

9. Small, N., 2007. Living well until you die: Quality of care and quality of life in Palliative and Dementia care. Annals Of The New York Academy Of Sciences, Volume 1114, pp. 194-203.

10. Garrett, C., 2005. Impacto sócio-económico da doença de Alzheimer. In: A doença de alzheimer e outras demências em Portugal. Lisbon: Lidel - Edições Técnicas, Lda.

11. Byrne-Davis, L., Bennett, P. \& Wilcock, G., 2006. How are quality of life ratings made? Toward a model of quality of life in people with dementia. Quality of Life Research, 15(5), pp. 855-65.

12. WHOQOL Group, 1997. Measuring Quality of Life, Geneva: World Health Organization.

13. Naglie, G., 2007. Quality of life in Dementia. Canadian Journal of Neurological Sciences, 34(Supplement 1), pp. S57-S61.

14. Hughes, C. et al., 1982. A new clinical scale for the staging of dementia. The British Journal of Psychiatry, Volume 140, pp. 566-72.

15. Aaronson, N. et al., 2002. Assessing health status and quality-of-life instruments: attributes and review criteria. Quality of life Research, 11(3), pp. 193-205.

16. Terwee, C. et al., 2007. Quality criteria were proposed for measurement properties of health status questionnaires. Journal of Clinical Epidemiology, 6o(1), pp. 34-42.

17. Matos, L., 2011. Medo da Queda, Estado emocional, qualidade de vida e contexto, Lisbon: University of Lisbon: Faculty of Psicology (Masters Degree).

18. Bárrios, H. et al., 2013. Quality of life in patients with cognitive impairment: validation of the quality of life - Alzheimer's Disease scale in Portugal. International Psychogeriatrics, 25(7), pp. 1085-96.

19. Pérola, S., 2007. Escala de Satisfação com a Vida (SWLS). In: Escalas e Testes na Demência. Coimbra: Grupo de estudos de Envelhecimento Cerebral e Demência, pp. 117-9.

20. Ankri, J. et al., 2003. Use of the EQ-5D among patient suffering from Dementia. Journal of Clinical Epidemiology, 56(11), pp. 1055-63.

21. Bhattacharya, S. et al., 2010. Generic and disease-specific measures of quality of life in patients with mild Alzheimer's disease. Dementia and geriatric cognitive disorders, 30(4), pp. 327-333.

22. López-Bastida, J., Serrano-Aguilar, P., Perestelo-Perez, L. \& Oliva-Morena, J., 2006. Social-economic costs and quality of life of Alzheimer Disease in the Canary Islands, Spain. Neurology, 67(12), pp. 2186-91.

23. Martín-García, S. et al., 2013. Comorbidity, health status, and quality of life in institutionalized older people with and without dementia. International Psychogeriatrics, 25(7), pp. 1077-84. 